\title{
High fat diet altered cardiac metabolic gene profile in Psammomys obesus gerbils
}

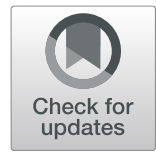

\author{
Abdelhamid Sahraoui ${ }^{1,2,3}$, Céline Dewachter ${ }^{1,4}$, Grégory Vegh ${ }^{1}$, Kathleen Mc Entee ${ }^{1}$, Robert Naeije ${ }^{1}$, \\ Souhila Aouichat Bouguerra ${ }^{2}$ and Laurence Dewachter ${ }^{1 *}$ (D)
}

\begin{abstract}
Background: In metabolic disorders, myocardial fatty infiltration is critically associated with lipotoxic cardiomyopathy.

Methods: Twenty Psammomys obesus gerbils were randomly assigned to normal plant or high fat diet. Sixteen weeks later, myocardium was sampled for pathobiological evaluation.

Results: A sixteen-week high fat diet resulted in myocardial structure disorganization, with collagen deposits, lipid accumulation, cardiomyocyte apoptosis and inflammatory cell infiltration. Myocardial expressions of glucose transporter GLUT1 and pyruvate dehydrogenase (PDH) inhibitor, PDH kinase (PDK)4 increased, while insulin-regulated GLUT4 expression remained unchanged. Myocardial expressions of molecules regulating fatty acid transport, CD36 and fatty acid binding protein (FABP)3, were increased, while expression of rate-controlling fatty acid $\beta$-oxidation, carnitine palmitoyl transferase (CPT)1B decreased. Myocardial expression of AMP-activated protein kinase (AMPK), decreased, while expression of peroxisome proliferator activated receptors (PPAR)- $a$ and $-\gamma$ did not change.

Conclusion: In high fat diet fed Psammomys obesus, an original experimental model of nutritionally induced metabolic syndrome mixing genetic predisposition and environment interactions, a short period of high fat feeding was sufficient to induce myocardial structural alterations, associated with altered myocardial metabolic gene expression in favor of lipid accumulation.
\end{abstract}

Keywords: Lipotoxicity, Psammomys obesus, High fat diet, Cardiomyopathy, Apoptosis

\section{Background}

In the normal adult heart, fatty acids are major substrates for ATP generation, while glucose oxidation provides a lesser contribution to energy production [1]. Besides an altered metabolic profile, chronic high fat diet consumption contributes to dysregulated glucose and fatty acid metabolism, leading to overall dysregulated energy homeostasis [2]. In the heart, this is associated with a variety of adaptations and alterations in myocardial structure and function occurring in subjects as adipose

\footnotetext{
* Correspondence: Idewacht@ulb.ac.be

'Laboratory of Physiology and Pharmacology, Faculty of Medicine, Université Libre de Bruxelles, 808, Lennik Road, 1070 Brussels, Belgium

Full list of author information is available at the end of the article
}

tissue and lipids accumulate abnormally, even in the absence of comorbidities such as type 2 diabetes or hypertension [3]. Obesity has been associated with increased myocardial lipid accumulation $[4,5]$, which was correlated with diastolic dysfunction [6]. Increased myocardial intracellular levels of triglycerides were also commonly described in various experimental models of obesity [7, 8]. Chronic exposure to high plasma levels of free fatty acids may cause accumulation of toxic lipid intermediates within cardiomyocytes, which has been related to cardiac lipotoxicity [9]. However, mechanisms leading to obesity-induced cardiomyopathy remain largely unknown [10].

C C The Author(s). 2020 Open Access This article is licensed under a Creative Commons Attribution 4.0 International License, which permits use, sharing, adaptation, distribution and reproduction in any medium or format, as long as you give appropriate credit to the original author(s) and the source, provide a link to the Creative Commons licence, and indicate if changes were made. The images or other third party material in this article are included in the article's Creative Commons licence, unless indicated otherwise in a credit line to the material. If material is not included in the article's Creative Commons licence and your intended use is not permitted by statutory regulation or exceeds the permitted use, you will need to obtain permission directly from the copyright holder. To view a copy of this licence, visit http://creativecommons.org/licenses/by/4.0/ The Creative Commons Public Domain Dedication waiver (http://creativecommons.org/publicdomain/zero/1.0/) applies to the data made available in this article, unless otherwise stated in a credit line to the data. 
Due to its particular pathologic adaptation to nutrient excess, Psammomys obesus is an original nutritionally controlled and genetically predetermined experimental model of obesity and metabolic syndrome [11]. Indeed, on its natural diet composed of halophilic plants, Psammomys obesus is healthy, with a metabolicendocrine system adapted to desert life. In captivity, they spontaneously and naturally develop diabetes, dyslipidemia and obesity, when fed on a standard laboratory rodent chow diet [11]. This pathologic adaptation to nutrient excess may represent a reliable experimental model for studying the mechanisms underlying the predisposition to develop insulin resistance and metabolic syndrome in humans who evolve from scarcity to abundant food intake [12]. In these animals, a short period of time with high fat diet resulted in an important weight gain and increased circulating levels of fatty acids, as well as altered myocardial expression of calciumhandling contraction proteins [13].

In this context, the objective of the present study was to explore whether a high fat diet could induce cardiac alterations in structure, energy metabolism and cardiomyocyte viability in these wild rodents with a genetic predisposition to develop obesity.

\section{Methods}

\section{Animal model}

Adult Psammomys obesus gerbils were captured in the Algerian region of Beni-Abbes ( $30^{\circ} 7$ latitude north and $2^{\circ} 10$ longitude west) and housed in individual cages in a 12-h light/dark cycle for 2 weeks. During this period of acclimation, the animals were fed with their natural food composed of halophilic plants [14, 15]. Thereafter, sexmatched eight-week old gerbils weighting $93 \pm 9 \mathrm{~g}$ were divided in 2 groups as follows: 1) control animals were fed with normal diet of natural halophilic plants (Salicornia; composition of the halophilic plants: water $80.8 \mathrm{~g}$; mineral salts $6.9 \mathrm{~g}$; lipids $0.4 \mathrm{~g}$; proteins $3 \mathrm{~g}$; carbohydrates $8.4 \mathrm{~g}$ and $45-50 \mathrm{kcal} / 100 \mathrm{~g}$ ); 2) the other group of animals received a high fat diet, comprising halophilic plants plus the daily addition of one-quarter $(5 \mathrm{~g})$ of cooked egg yolk (composition of cooked egg yolk: water 40-46 g; proteins 13.5-17.5 g; carbohydrates 0.2 g; lipids 30-31 g; cholesterol $1.2-1.3 \mathrm{~g}$ and $370-400 \mathrm{kcal} / 100 \mathrm{~g}$ ) during 16 weeks.

At baseline and after a sixteen-week high fat diet, animals were bled from the retro-orbital venous plexus. Blood samples were immediately centrifuged at 3000 rpm on dried tubes. At the end of the protocol, the animals were sacrificed by decapitation. Hearts were immediately dissected, snap-frozen in liquid nitrogen and kept at $-80{ }^{\circ} \mathrm{C}$ for pathobiological analysis $(n=10$ in each group) or after three-day fixation in Bouin's aqueous solution, embedded in toto in paraffin for histopathological evaluation ( $n=10$ in each group).

\section{Biochemical analysis}

Glucose, triglyceride and total cholesterol concentrations were determined with BIOSYSTEM kits (Barcelona, Spain) in plasma samples, according to manufacturer's instructions. Plasma were used for the assay of lipoproteins on agarose gel by the method of Kalwakami [16]. Plasma creatine Phosphokinase (CPK) levels were measured using COBAS INTEGRA Analyzer (Roche; CA, USA).

\section{Cardiac morphometry}

Five-micrometer myocardial sections were taken along the longitudinal axis of the heart and stained with hematoxyllin-eosin for overall morphological analysis, as previously described [17]. Masson's Trichrome staining was used to assess collagen accumulation and fibrosis within myocardial sections.

\section{Immunohistochemistry: Detection of myocardial cells undergoing apoptosis}

Cardiac apoptotic cells were detected by Terminal Deoxynucleotidyl Transferase dUTP Nick-End Labeling (TUNEL) staining using the ApopTagPlus Peroxidase In Situ Apoptosis Detection Kit (Chemicon, Temecula, CA), according to the manufacturer's instructions. Negative control run without TdT enzyme and positive control pretreated with DNase-I were tested. For each cardiac sample, ten different randomly chosen fields were examined. Cardiac apoptotic rate was calculated as the ratio of apoptotic nuclei (TUNEL-positive or brown nuclei) to total nuclei (brown + blue nuclei) $(\times 100$ to be expressed in percentage). All counts were performed by two independent investigators in blinded manner. Mean value was used for analysis.

\section{Real-time quantitative polymerase chain reaction (RTQ- PCR)}

Total RNA was extracted from snap-frozen myocardial tissue using QIAGEN RNeasy Mini kit (QIAGEN, Hilden, Germany), according to the manufacturer's instructions. RNA concentration was determined by standard spectrophotometric technique and RNA integrity was assessed by visual inspection of GelRed (Biotium, Hayward, California)-stained agarose gels. Reverse transcription was performed using random hexamer primers and Superscript II Reverse Transcriptase (Invitrogen, Merelbeke, Belgium), according to the manufacturer's instructions.

For RTQ-PCR, sense and antisense primers (Table 1) were designed using Primer3 program for Rattus norvegicus solute carrier family 2 members 1 (Slc2a1 or 
Table 1 Primers used for real-time quantitative polymerase chain reaction (RT-QPCR) in myocardial tissue from Psammomys obesus gerbils

\begin{tabular}{|c|c|c|}
\hline Genes & & Primer sequences \\
\hline \multirow[t]{2}{*}{ Solute carrier family 2 members 1 (SIc2a $\mathbf{1}$ or GLUT1) } & Sense & GTGGGCCTCTTTGTTAATCG \\
\hline & Antisense & CATAAGCACGGCAGACACAA \\
\hline \multirow[t]{2}{*}{ Solute carrier family 2 members 4 (SIc2a4 or GLUT4) } & Sense & GAGTTAGCTGGGGTGGAACA \\
\hline & Antisense & ACCGAGACCAACGTGAAGAC \\
\hline \multirow[t]{2}{*}{ Carnitine palmitoyltransferase-1B (CPT1B) } & Sense & AAGAACACGAGCCAACAAGC \\
\hline & Antisense & ACCATACCCAGTGCCATCAC \\
\hline \multirow[t]{2}{*}{ Fatty acid binding protein 3 (FABP3) } & Sense & TCAAGTCGGTCGTGACACTG \\
\hline & Antisense & TCCCATCACTTAGTTCCCGTG \\
\hline \multirow[t]{2}{*}{ Fatty acid translocase (CD36) } & Sense & TTCAAGGTGTGCTCAACAGC \\
\hline & Antisense & ACCCCACAAGAGTTCCTTCA \\
\hline \multirow[t]{2}{*}{ AMP-activated protein kinase (AMPK) } & Sense & TTCGGGAAAGTGAAGGTGGG \\
\hline & Antisense & TCTCTGCGGATTITCCCGAC \\
\hline \multirow[t]{2}{*}{ Pyruvate dehydrogenase kinase 4 (PDK4) } & Sense & TTCCAGGCCAACCAATCCAC \\
\hline & Antisense & TGGCCCTCATGGCATTCTTG \\
\hline \multirow[t]{2}{*}{ Uncoupling protein 3 (UCP3) } & Sense & CGCCAGATGAGTTTTGCCTC \\
\hline & Antisense & CTGGAGTGGTCCGTTCCTIT \\
\hline \multirow[t]{2}{*}{ Peroxisome proliferator activated receptor-alpha (PPAR-a) } & Sense & TTAGAGGCGAGCCAAGACTG \\
\hline & Antisense & CAGAGCACCAATCTGTGATGA \\
\hline \multirow[t]{2}{*}{ Peroxisome proliferator activated receptor-gamma (PPAR- $\boldsymbol{\gamma}$ ) } & Sense & GCGCTAAATTCATCTTAACTCCCA \\
\hline & Antisense & CTGTGTCAACCATGGTAATTTCAGT \\
\hline \multirow[t]{2}{*}{ Insulin receptor substrate 1 (IRS1) } & Sense & ATGAACATCAGACGCTGTGG \\
\hline & Antisense & TCATCCACTTGCATCCAGAA \\
\hline \multirow[t]{2}{*}{ Insulin receptor substrate 2 (IRS2) } & Sense & CGGATTTGGAAGAGGAGAGA \\
\hline & Antisense & GAGTGATGAGGCTGGGTATGA \\
\hline \multirow[t]{2}{*}{ Natriuretic peptide B (NPPB) } & Sense & GACGGGCTGAGGTTGTTITA \\
\hline & Antisense & ACTTGAGAGGTGGTCCCAGA \\
\hline \multirow[t]{2}{*}{ Hypoxanthine phosphoribosyl transferase-1 (HPRT1) } & Sense & ACAGGCCAGACTITGTTGGA \\
\hline & Antisense & TCCACTITCGCTGATGACCAC \\
\hline
\end{tabular}

GLUT1) and 4 (Slc2a4 or GLUT4), carnitine palmitoyltransferase1B (CPT1B), fatty acid translocase CD36, fatty acid binding protein 3 (FABP3), peroxisome proliferator activated receptors (PPAR) -alpha and -gamma, AMP-activated protein kinase (AMPK), pyruvate dehydrogenase kinase (PDK) 4, uncoupling protein (UCP) 3 , insulin receptor substrates (IRS) 1 and 2, natriuretic peptide $\mathrm{B}$ (NPPB) and hypoxanthine phosphoribosyl transferase (HPRT) 1 mRNA sequences. To avoid inappropriate amplification of residual genomic DNA, intron-spanning primers were selected when exon sequences were known. For each sample, amplification reaction was performed in triplicate using SYBR Green PCR Master Mix (Quanta Biosciences, Gaithersburg, MD, USA), specific primers and diluted template cDNA. Result analysis was performed using an iCycler System (BioRad Laboratories). Relative quantification was achieved with the comparative $2^{-\Delta \Delta \mathrm{Ct}}$ method by normalization with the housekeeping gene (HPRT1). Results were expressed as relative fold increase over the mean value of relative mRNA expression of 16-week normal diet fed control group arbitrary fixed to 1 .

\section{Statistical analysis}

All data were expressed as mean \pm standard error of the mean (SEM). Statistical analyses were performed using StatView 5.0 Software. Intergroup differences were assessed by one-way analysis of variance (one-way ANOVA) followed by Student's t-test. $p<0.05$ was considered statistically significant. 


\section{Results}

\section{Chronic high fat diet caused body weight gain and} systemic hyperlipidemia

As illustrated in Table 2, baseline body weight and biochemical parameters were similar between the two study groups of Psammomys obesus gerbils. After sixteen-week high fat diet, body weight increased more than in normal diet-fed animals (Table 2).

In terms of biochemical parameters, sixteen-week high fat diet was associated with increased plasma levels of lipids, including triglycerides, total cholesterol, lowdensity (LDL-c) and high-density lipoprotein cholesterol (HDL-c) (Table 2). Plasma atherogenic Castelli's Risk Index-I (assessed as the ratio between total cholesterol and HDL-cholesterol) and -II (assessed as the ratio between LDL-cholesterol and HDL-cholesterol) were calculated. They were found to be significantly increased after sixteen-week high fat diet (Table 2). There was only a trend (but not significant) of higher plasma level of glucose (increased by $32 \%$ compared to normal diet) (Table 2). Plasma levels of CPK were increased (Table 2).

\section{Myocardial architecture was altered after sixteen-week high fat diet}

As illustrated in Fig. 1a and b, hematoxylin and eosin staining showed normal histological heart architecture with myofibrils and muscle bundles in myocardial sections from normal diet fed animals. After sixteen-week high fat diet, there was myocardial accumulation of infiltrating inflammatory cells and apoptosis of cardiac myocytes (Fig. 1c). This was associated with lipid deposit accumulation within the myocardium (Fig. 1d and e), which strongly suggest myocardial lipotoxicity probably contributing to depressed cardiac function and cardiomyopathy [18].
To assess fibrosis and collagen deposit, Masson's Trichrome staining was performed. In animals fed with normal diet, cardiac cells were arranged orderly, with a structured cardiac muscle fiber organization and little collagen fiber deposit even at perivascular area (Fig. 2a and b). Sixteen-week high fat diet induced myocardial structural disorganization with cardiomyocyte loss (Fig. 2c and e), myocardial diffuse interstitial (Fig. 2e) and perivascular fibrosis (Fig. 2c and d), associated with myocardial accumulation of infiltrating cells (Fig. 2e) and lipid deposits (Fig. 2f).

\section{Cardiomyocyte apoptosis was induced by sixteen-week high fat diet}

To assess whether this myocardial accumulation of lipids could be associated with cardiac cell apoptosis, a TUNEL staining was performed in myocardial sections. As illustrated in Fig. 3a, sixteen-week high fat diet induced diffuse apoptosis in cardiomyocytes. The apoptotic rate was increased in the myocardium of Psammomys obesus fed with high fat diet (Fig. 3b).

\section{High fat diet altered myocardial expression of molecules implicated in glucose and lipid metabolism}

To determine the effects of a relative short period of high fat diet on expression profile of genes modulating cardiac energy production, including cardiac glucose and fatty acid metabolism, as well as insulin signaling, RTQPCR experiments were performed. Sixteen-week high fat diet increased myocardial gene expression of the major glucose transporter GLUT1, while expression of GLUT4, an insulin-regulated facilitative glucose transporter, remained unchanged (Fig. 4a). Myocardial expression of CD36, a major cellular regulator of fatty acid transport, and FABP3, an intracellular fatty acid-binding protein participating in fatty acid uptake and

Table 2 Sixteen-week evolution of bodyweight and plasma biochemical parameters after high fat and normal diet feeding in Psammomys obesus gerbils

\begin{tabular}{|c|c|c|c|c|c|c|}
\hline & \multicolumn{3}{|l|}{ Baseline } & \multicolumn{3}{|l|}{ After 16 weeks } \\
\hline & Normal diet $(\boldsymbol{n}=10)$ & Hight fat diet $(\boldsymbol{n}=10)$ & & Normal diet $(\boldsymbol{n}=10)$ & High fat diet $(\boldsymbol{n}=10)$ & \\
\hline Bodyweight (in g) & $91 \pm 3$ & $94 \pm 2$ & NS & $106 \pm 5$ & $113 \pm 4$ & $*$ \\
\hline Glucose (in g/L) & $0.62 \pm 0.06$ & $0.59 \pm 0.03$ & NS & $0.60 \pm 0.07$ & $0.79 \pm 0.10$ & NS \\
\hline Triglycerides (in g/L) & $0.58 \pm 0.05$ & $0.64 \pm 0.05$ & NS & $0.52 \pm 0.06$ & $0.97 \pm 0.16$ & $*$ \\
\hline Total cholesterol (in $\mathrm{g} / \mathrm{L}$ ) & $0.61 \pm 0.09$ & $0.55 \pm 0.03$ & NS & $0.70 \pm 0.08$ & $4.29 \pm 0.98$ & $*$ \\
\hline LDL-cholesterol (ing/L) & $0.12 \pm 0.03$ & $0.12 \pm 0.01$ & NS & $0.15 \pm 0.04$ & $3.25 \pm 0.83$ & $* *$ \\
\hline HDL-cholesterol (in g/L) & $0.35 \pm 0.06$ & $0.34 \pm 0.02$ & NS & $0.46 \pm 0.05$ & $1.06 \pm 0.12$ & $* *$ \\
\hline Castelli risk index-I & $1.90 \pm 0.45$ & $1.64 \pm 0.06$ & NS & $1.87 \pm 0.37$ & $3.83 \pm 0.76$ & * \\
\hline Castelli risk index-II & $0.69 \pm 0.47$ & $0.35 \pm 0.04$ & NS & $0.31 \pm 0.05$ & $2.72 \pm 0.63$ & $*$ \\
\hline CPK (IU/L) & $375 \pm 42$ & $361 \pm 55$ & NS & $345 \pm 41$ & $646 \pm 106$ & * \\
\hline
\end{tabular}

Values are presented as means \pm SEM. ${ }^{* *} 0.001<P<0.05,{ }^{*} 0.01<P<0.05$ high fat versus normal diet feeding at baseline and after 16 -week feeding. $L D L$ means low-density lipoprotein, HDL high-density lipoprotein; Castelli risk index-I calculated as the ratio between total cholesterol and HDL-cholesterol levels; Castelli risk index-II calculated as the ratio between LDL-cholesterol and HDL-cholesterol levels; CPK creatine phosphokinase, NS not significant 


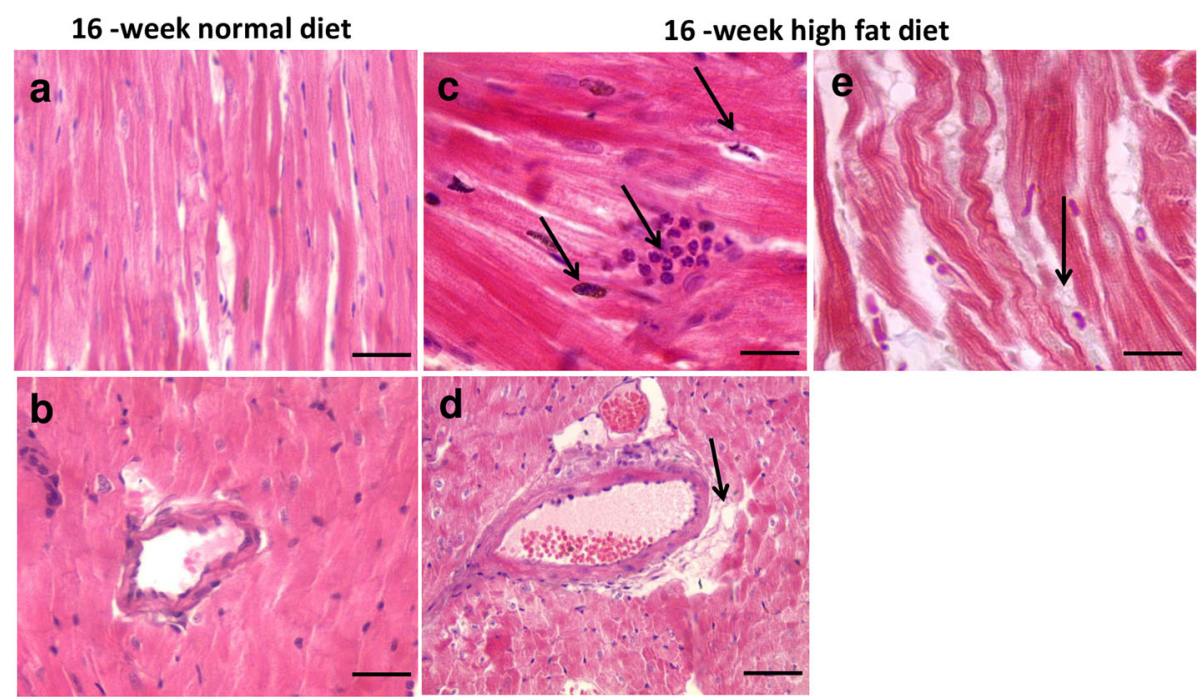

Fig. 1 Representative hematoxylin and eosin-stained myocardial sections from Psammomys obesus gerbils fed with normal diet (a, b) or high fat diet (c-e) during 16 weeks. Myocardial sections were obtained at 1000-fold (a-d; Scale bars: $20 \mu \mathrm{m}$ ) and 400-fold (e; Scale bar: 50 m)

magnification. In normal diet-fed animals, myocardial sections showed normal histological heart architecture with myofibrils and muscle bundles (a, b). In 16-week high fat diet fed animals, hematoxylin and eosin stained-myocardial sections showed infiltrating inflammatory cells (c) and lipid accumulation $(\mathbf{d}, \mathbf{e})$

intracellular transport, were increased, while expression of the rate-controlling enzyme of fatty acid $\beta$-oxidation pathway, CPT1B, decreased (Fig. 4b). All these results suggest altered myocardial expression profile of energy production mediators in favor of myocardial fatty acid uptake and accumulation (decreased fatty acid $\beta$ oxidation) after sixteen-week high fat diet in Psammomys obesus gerbils.
To understand better mechanisms controlling the expression of these metabolic mediators, expression of nuclear transcription factors and enzymes implicated in lipid and glucose metabolism regulation and adipocyte differentiation were evaluated. As illustrated in Fig. 4c, myocardial expression of PPAR- $\alpha$ and $-\gamma$ did not change after chronic high fat diet. However, expressions of AMPK, a cellular energy sensor, and of UCP3, a

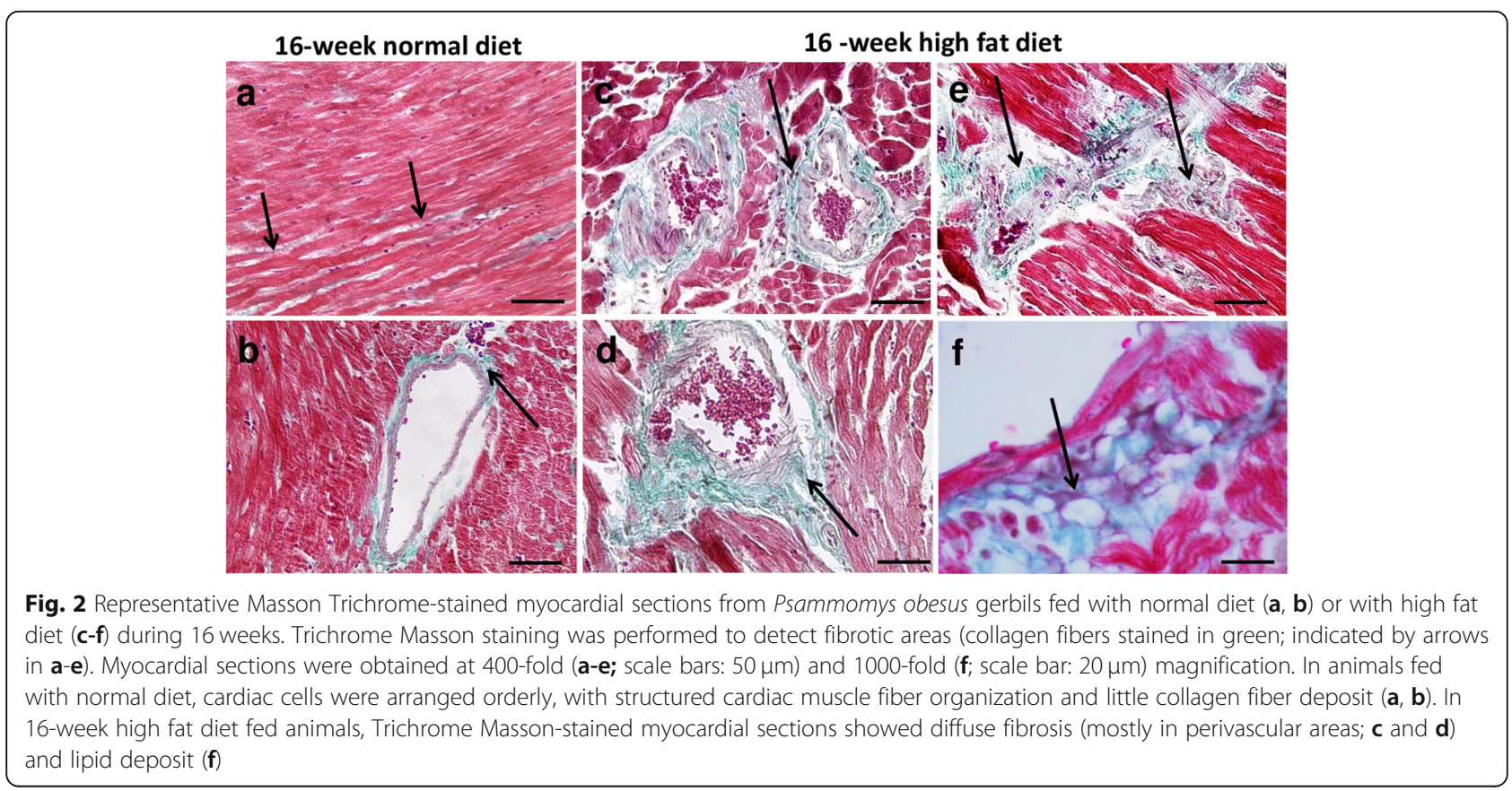



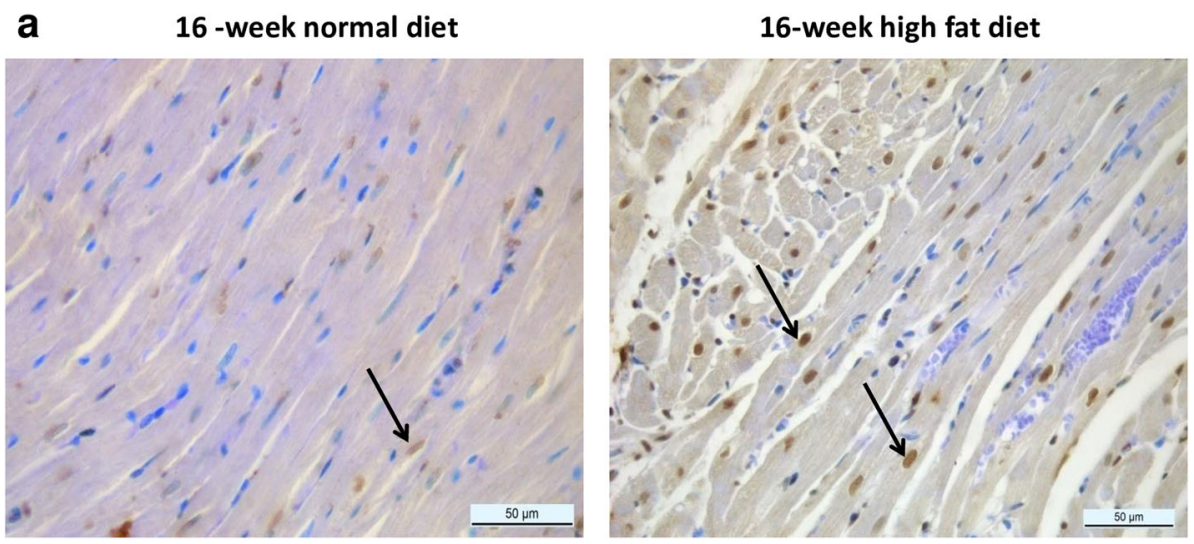

b
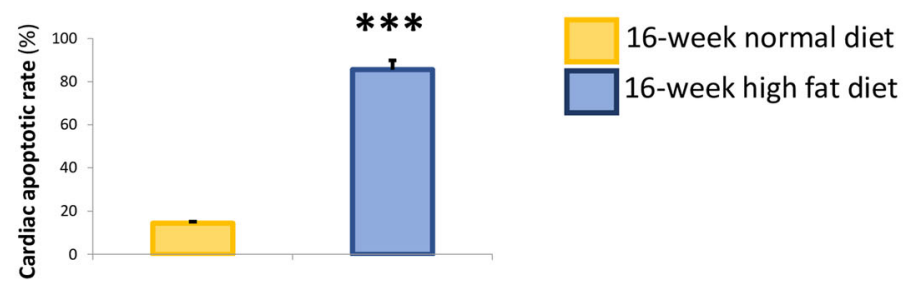

Fig. 3 Myocardial activation of apoptotic processes assessed by terminal deoxynucleotidyl transferase biotin-dUTP nick-end labeling (TUNEL) in Psammomys obesus gerbils fed with normal diet or high fat diet during 16 weeks. Myocardial sections were obtained at $400-f o l d$ (a; Scale bars: $50 \mu \mathrm{m}$ ). Cardiac apoptotic rate (in percentage; $\mathbf{b}$ ) was evaluated as the ratio between the number of terminal deoxynucleotidyl transferase biotindUTP nick-end labeling-positive cardiomyocytes (brown nuclei mentioned by arrows) and the total number of cardiomyocytes (brown + blue nuclei) in 16-week normal ( $n=10$; yellow bars) and high fat diet ( $n=10$; blue bars)-fed animals. Data are expressed as mean \pm SEM.*** $P<0.001$ versus the normal diet fed animals

mitochondrial transporter implicated in energy balance control, decreased in the heart of animals fed with high fat diet, while expression of PDK4, which phosphorylates (and thus deactivates) pyruvate dehydrogenase (PDH) and inhibits glucose oxidation, was increased (Fig. 4d). Myocardial expressions of IRS1 and 2 did not change (Fig. 4e).

\section{Myocardial expression of wall stretch responsive gene, the natriuretic peptide $B$ (BNP)}

When the heart is stretched, BNP concentration increases markedly, indicating that the heart is working harder and having more trouble meeting the body's demands, such as in heart failure [19]. In the present study, gene expression of NPPB, the precursor of BNP, was increased in the myocardium of high fat diet-fed animals (Fig. 5).

\section{Discussion}

The present results show that sixteen-week high fat diet results in severe alterations of cardiac structure, with collagen and lipid accumulation and diffuse activation of apoptotic processes in Psammomys obesus gerbils, wild rodents with a genetic predisposition to develop obesity, diabetes and metabolic syndrome. This was associated with altered cardiac expression of molecules regulating energy metabolism in favor of cardiac lipid accumulation, with increased expressions of CD36 and FABP3, both implicated in cellular fatty acid transport, and of PDK4, a key regulator of glucose oxidation, while expressions of CPT1B, a rate-controlling enzyme of fatty acid $\beta$-oxidation and of a key cellular energy sensor AMPK decreased.

A sixteen-week high fat diet resulted in the development of obesity associated with increased circulating levels of triglycerides, total cholesterol, LDL- and HDLcholesterol, which strongly suggest major cardiovascular risks in these animals [20,21]. This was confirmed by higher values of Castelli's risk index-I and -II after sixteen-week high fat diet [22]. This is consistent with previous studies showing rapid development of obesity and metabolic syndrome after high fat diet in Psammomys obesus [13,14, 23], even if a characteristic diabetic profile was not found in the present study. Indeed, glucose tolerance seemed to be preserved in these animals, because glucose levels only slightly increased. This apparent discrepancy has already been described in Psammomys obesus removed from their natural halophilic plant diet evolving variably overtime [15]. Genetic background also probably contributed to the rapid cardiac alterations in cardiac morphometry and energy substrate use. However, little is known about these genetic 

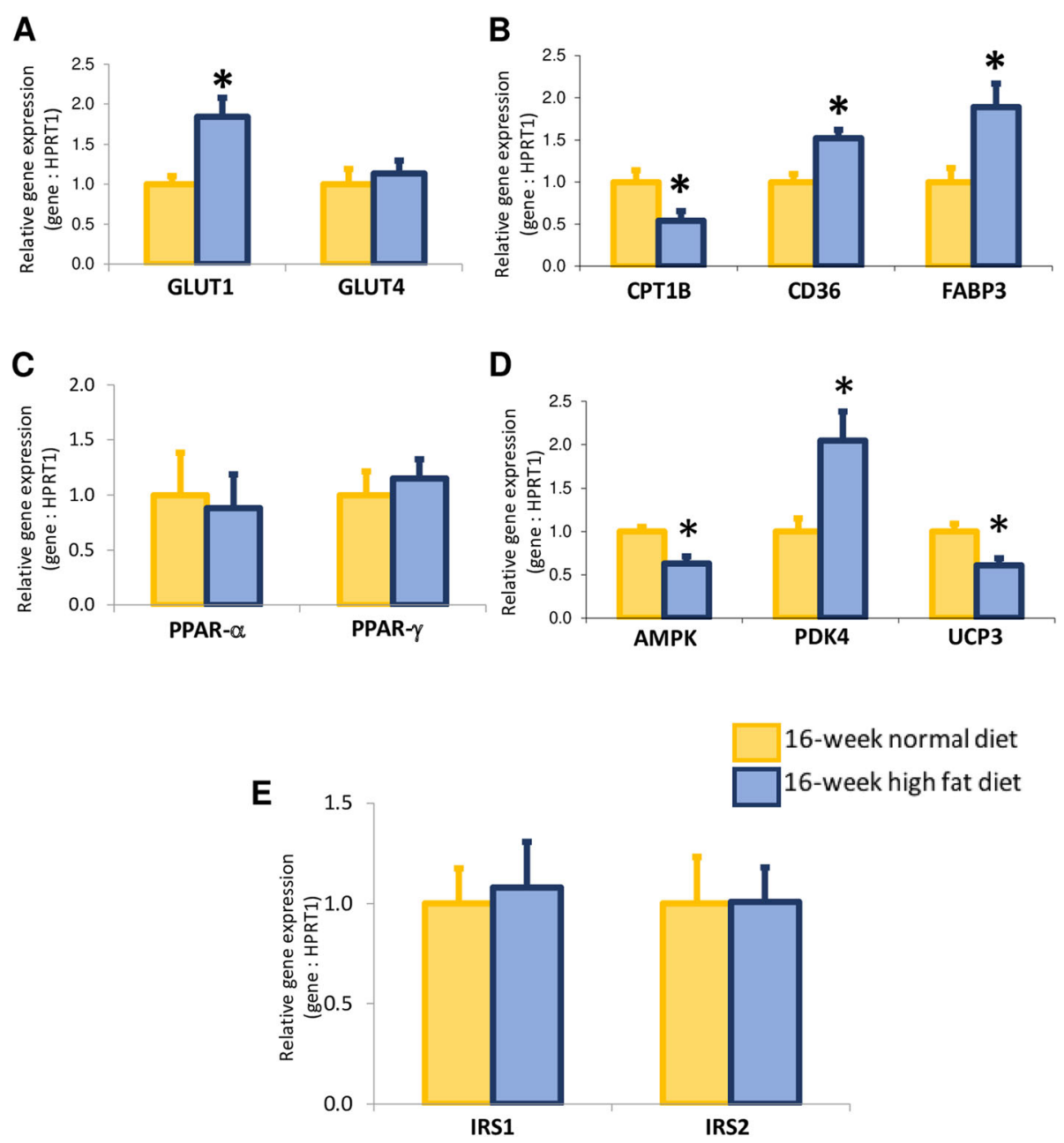

Fig. 4 Myocardial expression of genes implicated in uptake and metabolism of glucose and fatty acids, including the solute carrier family 2 members 1 (SIc2a1 also called GLUT1; a) and 4 (SIc2a4 also called GLUT4; a); the carnitine palmitoyltransferase1B (CPT1B; b), the CD36 (b) and the fatty acid binding protein 3 (FABP3; b); of transcription factors implicated in cardiac metabolism regulation, including the peroxisome proliferator activated receptors-alpha (PPAR-a; $\mathbf{c}$ ) and -gamma (PPAR- $;$; $)$; the protein kinase AMP-activated (AMPK; d), pyruvate dehydrogenase kinase 4 (PDK4; $\mathbf{d}$ ) and uncoupling protein 3 (UCP3; d); and of insulin receptors (IRS) 1 and 2 (e) in 16-week normal ( $n=10$; yellow bars) versus high fat ( $n=10$; blue bars) diet fed Psammomys obesus gerbils. Values are expressed as mean \pm SEM. ${ }^{*} 0.01<P<0.05$, high fat diet- versus normal diet-fed Psammomys obesus animals

determinants. Genome sequencing of Psammomys obesus revealed a mutationally biased chromosome region probably involved in ecological adaptation and constraint in these animals [16]. However, to date, the link with the present results remain elusive.

After high fat diet, histological examination of the heart revealed interstitial and perivascular fibrosis and inflammatory cell infiltration, associated with lipid accumulation and cardiomyocyte apoptosis. In humans, obesity has been related to epicardial fat deposition and intra-myocardial fatty infiltration [17]. In the heart, accumulation of intramyocellular triglycerides was also described in experimental models of obesity [7, 8]. Elevated circulating levels of fatty acids have been strongly associated to myocardial lipid accumulation [18,
19] and even to lipotoxicity in cardiomyocytes for oxidized LDL-cholesterol [24]. Moreover, presence of triglycerides and lipid metabolites has been related to cardiac lipotoxicity and cardiomyocyte apoptosis. Then, apoptotic cells were replaced by extracellular matrix that leads to cardiac remodeling and dysfunction [25]. A positive correlation between cardiac lipid accumulation and dysfunction has been described giving rise to the term lipotoxic cardiomyopathy associated with obesity [26]. Usually, early stages of cardiomyopathy include cardiac hypertrophy, intracellular lipid accumulation, fibrosis and diastolic dysfunction, which evolves to systolic dysfunction with reduced ejection fraction [27]. In the present study, there was no evaluation allowing to correlate heart function and accumulation of fatty acids per 


\section{6-week normal diet}

\section{6-week high fat diet}

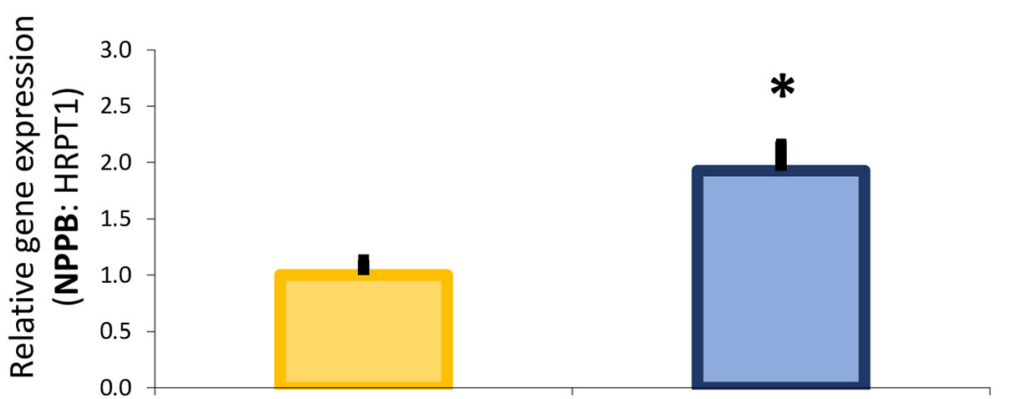

Fig. 5 Myocardial expression of cardiac stress-response gene, natriuretic peptide B (NPPB) in 16-week normal ( $n=10$; yellow bars) versus high fat ( $n=10$; blue bars) diet fed Psammomys obesus gerbils. Values are expressed as mean \pm SEM. ${ }^{*} 0.01<P<0.05$, high fat diet- versus normal diet-fed Psammomys obesus animals

se. However, cardiomyocyte hypertrophy [13] and apoptosis, lipid deposit accumulation and fibrosis, as well as increased CPK were found, all together probably contributing to cardiac dysfunction associated to chronic high fat diet in Psammomys obesus. Plasma cardiospecific biomarkers (such as CK-MB) allowing the evaluation of heart function should be evaluated in further studies.

The present results suggest that obesity promoted myocardial lipid accumulation though fatty acid oversupply and chronic hyperlipidemia. Cardiac metabolism depends primarily on fatty acid utilization for oxidative phosphorylation and ATP generation [26]. Fatty acids enter the cell via cell membrane fatty acid transporters, such as CD36 and FABP [28]. In the present study, myocardial expressions of CD36 and FABP3 were increased, which suggest exaggerated entry of fatty acids into cardiac cell cytoplasm. Because of its rate-controlling role in myocardial fatty acid metabolism, CD36 has been implicated in dysregulated fatty acid and lipid metabolism in high fat diet-induced cardiomyopathy [29]. In the heart of obese rats, persistent relocation of fatty acid transporters CD36 and FABP from the cytosol to the cell membrane has been described [30-32] and associated to chronic elevation in cardiac fatty acid uptake [33]. Genetic studies also indicated a crucial role for FABP in the pathogenesis of metabolic cardiomyopathy [34]. Expression of CPT1B, a key mitochondrial enzyme implicated in $\beta$-oxidation, was also decreased in the present study. This strongly suggests decreased fatty acid oxidation, since mitochondrial transfer of fatty acid oxidation mainly depends on CPT activity [28]. Sixteen-week high fat diet resulted in an imbalance between fatty acid uptake and consumption, contributing to intracellular lipid accumulation, which probably leads to cardiac cell dysfunction and death [35] and subsequent cardiomyopathy and heart failure [36]. Indeed, lipotoxic cardiomyopathy has been identified as the major mechanism through which patients with metabolic syndrome and obesity develop cardiac hypertrophy and dysfunction [37].

Even if fatty acid oxidation contributes to the majority of ATP generation in the normal adult heart, cardiomyocytes present high and flexible metabolic ability to use glucose. In the present study, chronic high fat diet was associated with increased myocardial expression of GLUT1, while GLUT4 expression did not change. Both GLUT1 and GLUT4 are the main glucose transporters in the heart. Increased GLUT1expression suggests a shift from an oxidative to a glycolytic metabolism [38]. In high fat diet-fed transgenic mice overexpressing GLUT1 specifically in the heart, cardiac dysfunction associated to excessive lipid accumulation was observed [39]. Expression of PDK4, the major regulator of PDH, was also increased, suggesting constrained glucose oxidation in the heart after high fat diet [40]. This is consistent with previous study showing increased PK4 expression along with increased availability of fatty acids over glucose after high fat diet [41]. Cardiac PDH inhibition resulted in metabolic re-programming with reduced glucose oxidation and increased glycolysis [42], suggesting maladaptive metabolic remodeling after chronic high fat diet. These changes in energy supply and use are probably accompanied with reduced myocardial ATP production, due to the lower number of ATP molecules generated during glycolysis compared with fatty acid oxidation, which probably contributes to altered cardiac efficiency and function.

In the present study, cardiac expressions of different key energy sensors, including PPAR's and AMPK was also evaluated. Expressions of PPAR- $\alpha$ and $-\gamma$ were not altered in the heart after high fat diet. PPARs play key 
roles in regulating fatty acid metabolism in the heart [43, $44]$, through the induction of expression of molecules involved in fatty acid oxidation, such as CD36 and CPT1 $[45,46]$. Myocardial PPAR- $\alpha$ overexpression mimicked lipotoxic cardiomyopathy [40], whereas PPAR- $\alpha$ knockdown attenuated it [47], suggesting its important role in lipotoxic cardiomyopathy pathogenesis. This apparent discrepancy with the present results has also been observed by others $[8,40,48]$. In diabetic mice, cardiac PPAR- $\alpha$ expression was not enhanced, while cardiac metabolism was altered $[8,40,48]$. This may be explained by the fact that alterations in cardiac metabolism could be independent of PPAR- $\alpha$, or that PPAR- $\alpha$ activity could be enhanced independently of gene expression. AMPK detects intracellular ATP/AMP ratio and plays a pivotal role in intracellular adaptation to energy stress. Here, expression of AMPK was decreased after high fat diet. Dysregulated AMPK has also been described in the heart of high fat diet-fed mice $[49,50]$. Cardiac AMPK activation has been involved in cardiac protection, accelerating ATP generation and attenuating ATP depletion, protecting against cardiac dysfunction and cardiomyocyte apoptosis [51, 52]. Inactivation of AMPK has been linked to the activation of apoptotic processes in cardiomyocytes [53], while AMPK activation reduced cardiomyocyte apoptosis and improved diabetic cardiomyopathy [54]. This is consistent with present results showing myocardial activation of apoptosis together with decreased AMPK expression after high fat diet.

UCP3 is a mitochondrial anion carrier protein with antioxidant properties known to stimulate fatty acid metabolism in muscle cells [55]. In high fat diet-fed animals, myocardial expression of UCP3 decreased. This is consistent with data showing either unchanged or decreased cardiac UCP3 levels in genetic models of obesity [56], despite increased mitochondrial uncoupling. In mice, genetic UCP3 deletion was associated to decreased myocardial ATP content [57], as well as worsening of cardiac function, increased cardiomyocyte death, and greater mortality after myocardial infarct [58]. Expression levels of insulin receptors was similar after a high fat diet. This is probably due to the fact that insulin resistance was not found in these animals. Increased expression of a heart failure marker BNP after a high fat diet was also shown in the present study. BNP is secreted by cardiomyocytes in response to stretching by increased blood volume. Increased expression of BNP precursor strongly suggests cardiac dysfunction associated to altered cardiac metabolism, as natriuretic peptide secretion has been shown to increase in proportion to the severity of cardiac dysfunction [59, 60]. However, further investigations are necessary to determine if these metabolic alterations are implicated in cardiac dysfunction in this experimental model.

\section{Study strength and limitation}

Psammomys obesus is an original nutritionally controlled and genetically predetermined experimental model of metabolic syndrome, which is associated to sustained myocardial biological alterations [13]. However, heart function and plasma levels of cardiospecific biomarkers were not evaluated per se. This should be evaluated in further studies.

\section{Conclusions}

In conclusion, after a sixteen-week high fat diet, the heart of Psammomys obesus showed signs of lipotoxic cardiomyopathy, characterized by metabolic remodeling and detrimental metabolic switch leading to lipid accumulation. This unique experimental model of nutritionally induced metabolic syndrome allowed us to myocardial impact of high fat diet in animals with a genetic predisposition to develop rapidly obesity, type 2 diabetes and metabolic syndrome. It may prove useful for the study of the mechanisms underlying the predisposition to develop insulin resistance and metabolic syndrome in humans who evolve from scarcity to abundant food intake.

\section{Abbreviations \\ AMPK: AMP-activated protein kinase; CD36: Fatty acid translocase; CPK: Creatine phosphokinase; CPT1B: Carnitine palmitoyltransferase-1B; FABP3: Fatty acid binding protein 3; HDL-c: High-density lipoprotein cholesterol; HPRT1: Hypoxanthine phosphoribosyl transferase 1; IRS1: Insulin receptor substrate1; IRS2: Insulin receptor substrate2; LDL-c: Low-density lipoprotein cholesterol; NPPB: Natriuretic peptide B; PDH: Pyruvate dehydrogenase; PDK4: Pyruvate dehydrogenase kinase 4; PPAR- \\ a: Peroxisome proliferator activated receptors-alpha; PPAR- $\gamma$ : Peroxisome proliferator activated receptor-gamma; SIc2a1 or GLUT1: Solute carrier family 2 members 1; Slc2a4 or GLUT4: Solute carrier family 2 members 4; TUNEL: Terminal Deoxynucleotidyl Transferase dUTP Nick-End Labeling; UCP3: Uncoupling protein 3}

\section{Acknowledgments}

Not applicable.

\section{Authors' contributions}

Study conception and design: AS, SAB, LD - Acquisition of data: AS, GV, LD Analysis and interpretation of data: AS, CD, LD - Drafting of manuscript: AS, RN, LD - Critical revision: AS, CD, GV, KMC, RN, SAB, LD. The author(s) read and approved the final manuscript.

\section{Funding}

The present work was supported by grants from the Belgian Foundation for Cardiac Surgery.

\section{Availability of data and materials}

All relevant data generated and analyzed during the current study are included the present article.

\section{Ethics approval}

The present protocol was approved by the Institutional Animal Care Committee of the National Administration of the Algerian Higher Education and Scientific Research (DGRSDT; http://www.dgrsdt.dz). The permits and ethical rules were achieved according to the executive decree $n^{\circ} 10-90$ completing the executive decree $n^{\circ} 04-82$ of the Algerian Government, establishing the terms and approval modalities of animal welfare in animal facilities. 


\section{Consent for publication}

Not applicable.

\section{Competing interests}

The authors have declared that no competing interests.

\section{Author details}

'Laboratory of Physiology and Pharmacology, Faculty of Medicine, Université Libre de Bruxelles, 808, Lennik Road, 1070 Brussels, Belgium. ${ }^{2}$ Team of Cellular and Molecular Physiopathology, Faculty of Biological Sciences, Houari Boumediene University of Sciences and Technology, El Alia, Algiers, Algeria. ${ }^{3}$ Faculté des Sciences de la Nature et de la Vie \& des Sciences de la Terre, University Djilali Bounaama of Khemis Miliana, 44225 Khemis Miliana, Algeria. ${ }^{4}$ Department of Cardiology, Cliniques Universitaires de Bruxelles, Hôpital Académique Erasme, Bruxelles, Belgium.

Received: 1 December 2019 Accepted: 22 May 2020

Published online: 03 June 2020

\section{References}

1. Stanley WC, Lopaschuk GD, Hall JL, McCormack JG. Regulation of myocardial carbohydrate metabolism under normal and ischaemic conditions. Potential for pharmacological interventions. Cardiovasc Res. 1997:33(2):243-57.

2. Golay A, Bobbioni E. The role of dietary fat in obesity. International journal of obesity and related metabolic disorders. Int J Obes Relat Metab Disord. 1997;21(Suppl 3):S2-11.

3. Poirier P, Giles TD, Bray GA, Hong Y, Stern JS, Pi-Sunyer FX, Eckel RH, American Heart A. Obesity Committee of the Council on nutrition PA, metabolism: obesity and cardiovascular disease: pathophysiology, evaluation, and effect of weight loss: an update of the 1997 American Heart Association scientific statement on obesity and Heart disease from the obesity Committee of the Council on nutrition, physical activity, and metabolism. Circulation. 2006;113(6):898-918.

4. Zhou YT, Grayburn P, Karim A, Shimabukuro M, Higa M, Baetens D, Orci L, Unger RH. Lipotoxic heart disease in obese rats: implications for human obesity. Proc Natl Acad Sci U S A. 2000:97(4):1784-9.

5. Thakker GD, Frangogiannis NG, Bujak M, Zymek P, Gaubatz JW, Reddy AK, Taffet G, Michael LH, Entman ML, Ballantyne CM. Effects of diet-induced obesity on inflammation and remodeling after myocardial infarction. Am J Physiol Heart Circ Physiol. 2006;291(5):H2504-14.

6. Chiu HC, Kovacs A, Blanton RM, Han X, Courtois M, Weinheimer CJ, Yamada KA, Brunet S, Xu H, Nerbonne JM, et al. Transgenic expression of fatty acid transport protein 1 in the heart causes lipotoxic cardiomyopathy. Circ Res. 2005;96(2):225-33.

7. Christoffersen C, Bollano E, Lindegaard ML, Bartels ED, Goetze JP, Andersen CB, Nielsen LB. Cardiac lipid accumulation associated with diastolic dysfunction in obese mice. Endocrinology. 2003;144(8):3483-90.

8. Buchanan J, Mazumder PK, Hu P, Chakrabarti G, Roberts MW, Yun UJ, Cooksey RC, Litwin SE, Abel ED. Reduced cardiac efficiency and altered substrate metabolism precedes the onset of hyperglycemia and contractile dysfunction in two mouse models of insulin resistance and obesity. Endocrinology. 2005;146(12):5341-9.

9. Chess DJ, Stanley WC. Role of diet and fuel overabundance in the development and progression of heart failure. Cardiovasc Res. 2008;79(2):269-78.

10. Trivedi PS, Barouch LA. Cardiomyocyte apoptosis in animal models of obesity. Curr Hypertens Rep. 2008;10(6):454-60.

11. Chaudhary R, Walder KR, Hagemeyer CE, Kanwar JR. Psammomys obesus: a natural diet-controlled model for diabetes and cardiovascular diseases. Curr Atheroscler Rep. 2018;20(9):46.

12. Shafrir E, Ziv E, Kalman R. Nutritionally induced diabetes in desert rodents as models of type 2 diabetes: Acomys cahirinus (spiny mice) and Psammomys obesus (desert gerbil). ILAR J. National Research Council, Institute of Laboratory Animal Resources. 2006;47(3):212-24.

13. Sahraoui A, Dewachter C, de Medina G, Naeije R, Aouichat Bouguerra S, Dewachter L. Myocardial structural and biological anomalies induced by high fat diet in Psammomys obesus gerbils. PLoS One. 2016;11(2):e0148117.

14. Marquie G, Duhault J, Jacotot B. Diabetes mellitus in sand rats (Psammomys obesus). Metabolic pattern during development of the diabetic syndrome. Diabetes. 1984;33(5):438-43.
15. Kalderon B, Gutman A, Levy E, Shafrir E, Adler JH. Characterization of stages in development of obesity-diabetes syndrome in sand rat (Psammomys obesus). Diabetes. 1986;35(6):717-24.

16. Hargreaves AD, Zhou L, Christensen J, Marletaz F, Liu S, Li F, Jansen PG, Spiga E, Hansen MT, Pedersen SVH, et al. Genome sequence of a diabetesprone rodent reveals a mutation hotspot around the ParaHox gene cluster. Proc Natl Acad Sci U S A. 2017;114(29):7677-82.

17. Fitzgibbons TP, Czech MP. Epicardial and perivascular adipose tissues and their influence on cardiovascular disease: basic mechanisms and clinical associations. J Am Heart Assoc. 2014;3(2):e000582.

18. How OJ, Larsen TS, Hafstad AD, Khalid A, Myhre ES, Murray AJ, Boardman NT, Cole M, Clarke K, Severson DL, et al. Rosiglitazone treatment improves cardiac efficiency in hearts from diabetic mice. Arch Physiol Biochem. 2007; 113(4-5):211-20.

19. Peterson LR, Saeed IM, McGill JB, Herrero P, Schechtman KB, Gunawardena R, Recklein CL, Coggan AR, DeMoss AJ, Dence CS, et al. Sex and type 2 diabetes: obesity-independent effects on left ventricular substrate metabolism and relaxation in humans. Obesity (Silver Spring). 2012:20(4):802-10.

20. Kinosian B, Glick H, Preiss L, Puder KL. Cholesterol and coronary heart disease: predicting risks in men by changes in levels and ratios. J Investig Med. 1995;43(5):443-50.

21. Stampfer MJ, Sacks FM, Salvini S, Willett WC, Hennekens CH. A prospective study of cholesterol, apolipoproteins, and the risk of myocardial infarction. N Engl J Med. 1991;325(6):373-81.

22. Castelli WD. The lipid risk factor in hypertension and cardiovascular disease. Br J Clin Pharmacol. 1987:24(Suppl 1):59S-60S.

23. Bouguerra SA, Bourdillon MC, Dahmani Y, Bekkhoucha E. Non insulin dependent diabetes in sand rat (Psammomys obesus) and production of collagen in cultured aortic smooth muscle cells. Influence of insulin. Int J Exp Diabetes Res. 2001;2(1):37-46.

24. Chen JH, Lee MS, Wang CP, Hsu CC, Lin HH. Autophagic effects of Hibiscus sabdariffa leaf polyphenols and epicatechin gallate (ECG) against oxidized LDL-induced injury of human endothelial cells. Eur J Nutr. 2017;56(5):1963-81.

25. Wollert KC, Drexler $\mathrm{H}$. Regulation of cardiac remodeling by nitric oxide: focus on cardiac myocyte hypertrophy and apoptosis. Heart Fail Rev. 2002; 7(4):317-25

26. Reho JJ, Rahmouni K. Oxidative and inflammatory signals in obesityassociated vascular abnormalities. Clin Sci (Lond). 2017;131(14):1689-700.

27. Yancy CW, Jessup M, Bozkurt B, Butler J, Casey DE Jr, Colvin MM, Drazner MH, Filippatos GS, Fonarow GC, Givertz MM, et al. 2017 ACC/AHA/HFSA focused update of the 2013 ACCF/AHA guideline for the Management of Heart Failure: a report of the American College of Cardiology/American Heart Association task force on clinical practice guidelines and the Heart Failure Society of America. Circulation. 2017;136(6):e137-61.

28. Lopaschuk GD, Ussher JR, Folmes CD, Jaswal JS, Stanley WC. Myocardial fatty acid metabolism in health and disease. Physiol Rev. 2010;90(1):207-58.

29. Glatz JFC, Luiken J. Dynamic role of the transmembrane glycoprotein CD36 (SR-B2) in cellular fatty acid uptake and utilization. J Lipid Res. 2018;59(7): 1084-93.

30. Luiken JJ, Arumugam Y, Dyck DJ, Bell RC, Pelsers MM, Turcotte LP, Tandon NN, Glatz JF, Bonen A. Increased rates of fatty acid uptake and plasmalemmal fatty acid transporters in obese Zucker rats. J Biol Chem. 2001:276(44):40567-73.

31. Coort SL, Hasselbaink DM, Koonen DP, Willems J, Coumans WA, Chabowski A, van der Vusse GJ, Bonen A, Glatz JF, Luiken JJ. Enhanced sarcolemmal FAT/CD36 content and triacylglycerol storage in cardiac myocytes from obese zucker rats. Diabetes. 2004:53(7):1655-63.

32. Carley AN, Atkinson LL, Bonen A, Harper ME, Kunnathu S, Lopaschuk GD, Severson DL. Mechanisms responsible for enhanced fatty acid utilization by perfused hearts from type 2 diabetic db/db mice. Arch Physiol Biochem. 2007;113(2):65-75

33. Chabowski A, Coort SL, Calles-Escandon J, Tandon NN, Glatz JF, Luiken $J$ J, Bonen A. The subcellular compartmentation of fatty acid transporters is regulated differently by insulin and by AICAR. FEBS Lett. 2005:579(11): 2428-32.

34. Shearer J, Fueger PT, Wang Z, Bracy DP, Wasserman DH, Rottman JN. Metabolic implications of reduced heart-type fatty acid binding protein in insulin resistant cardiac muscle. Biochim Biophys Acta. 2008;1782(10): 586-92. 
35. Goldberg IJ, Trent CM, Schulze PC. Lipid metabolism and toxicity in the heart. Cell Metab. 2012;15(6):805-12.

36. Neubauer S. The failing heart--an engine out of fuel. N Engl J Med. 2007; 356(11):1140-51.

37. Schilling JD, Mann DL. Diabetic cardiomyopathy: bench to bedside. Heart Fail Clin. 2012:8(4):619-31.

38. Abel ED. Glucose transport in the heart. Front Biosci. 2004;9:201-15.

39. Yan J, Young ME, Cui L, Lopaschuk GD, Liao R, Tian R. Increased glucose uptake and oxidation in mouse hearts prevent high fatty acid oxidation but cause cardiac dysfunction in diet-induced obesity. Circulation. 2009;1 19(21): 2818-28.

40. Finck BN, Lehman JJ, Leone TC, Welch MJ, Bennett MJ, Kovacs A, Han X, Gross RW, Kozak R, Lopaschuk GD, et al. The cardiac phenotype induced by PPARalpha overexpression mimics that caused by diabetes mellitus. J Clin Invest. 2002;109(1):121-30.

41. Crewe C, Kinter M, Szweda LI. Rapid inhibition of pyruvate dehydrogenase: an initiating event in high dietary fat-induced loss of metabolic flexibility in the heart. PLoS One. 2013;8(10):e77280.

42. Chambers KT, Leone TC, Sambandam N, Kovacs A, Wagg CS, Lopaschuk GD, Finck BN, Kelly DP. Chronic inhibition of pyruvate dehydrogenase in heart triggers an adaptive metabolic response. J Biol Chem. 2011; 286(13):11155-62.

43. Vega RB, Kelly DP. Cardiac nuclear receptors: architects of mitochondrial structure and function. J Clin Invest. 2017;127(4):1155-64.

44. Son NH, Park TS, Yamashita H, Yokoyama M, Huggins LA, Okajima K Homma S, Szabolcs MJ, Huang LS, Goldberg IJ. Cardiomyocyte expression of PPARgamma leads to cardiac dysfunction in mice. J Clin Invest. 2007; 117(10):2791-801.

45. Schoonjans K, Peinado-Onsurbe J, Lefebvre AM, Heyman RA, Briggs M, Deeb S, Staels B, Auwerx J. PPARalpha and PPARgamma activators direct a distinct tissue-specific transcriptional response via a PPRE in the lipoprotein lipase gene. EMBO J. 1996;15(19):5336-48.

46. Son NH, Yu S, Tuinei J, Arai K, Hamai H, Homma S, Shulman Gl, Abel ED, Goldberg IJ. PPARgamma-induced cardiolipotoxicity in mice is ameliorated by PPARalpha deficiency despite increases in fatty acid oxidation. J Clin Invest. 2010;120(10):3443-54.

47. Finck BN, Han X, Courtois M, Aimond F, Nerbonne JM, Kovacs A, Gross RW, Kelly DP. A critical role for PPARalpha-mediated lipotoxicity in the pathogenesis of diabetic cardiomyopathy: modulation by dietary fat content. Proc Natl Acad Sci U S A. 2003:100(3):1226-31.

48. Daniels A, van Bilsen M, Janssen BJ, Brouns AE, Cleutjens JP, Roemen TH, Schaart G, van der Velden J, van der Vusse GJ, van Nieuwenhoven FA. Impaired cardiac functional reserve in type 2 diabetic $\mathrm{db} / \mathrm{db}$ mice is associated with metabolic, but not structural, remodelling. Acta Physiol (Oxf). 2010;200(1):11-22.

49. Lee WJ, Lee IK, Kim HS, Kim YM, Koh EH, Won JC, Han SM, Kim MS, Jo I, Oh GT, et al. Alpha-lipoic acid prevents endothelial dysfunction in obese rats via activation of AMP-activated protein kinase. Arterioscler Thromb Vasc Biol. 2005;25(12):2488-94

50. Lessard SJ, Chen ZP, Watt MJ, Hashem M, Reid JJ, Febbraio MA, Kemp BE, Hawley JA. Chronic rosiglitazone treatment restores AMPKalpha2 activity in insulin-resistant rat skeletal muscle. Am J Physiol Endocrinol Metab. 2006; 290(2):E251-7.

51. Valente AJ, Irimpen AM, Siebenlist U, Chandrasekar B. OxLDL induces endothelial dysfunction and death via TRAF3IP2: inhibition by HDL3 and AMPK activators. Free Radic Biol Med. 2014;70:117-28.

52. Lee SY, Ku HC, Kuo YH, Chiu HL, Su MJ. Pyrrolidinyl caffeamide against ischemia/reperfusion injury in cardiomyocytes through AMPK/AKT pathways. J Biomed Sci. 2015;22:18.

53. Zhuo XZ, Wu Y, Ni YJ, Liu JH, Gong M, Wang XH, Wei F, Wang TZ, Yuan Z, $\mathrm{Ma} A \mathrm{~A}$, et al. Isoproterenol instigates cardiomyocyte apoptosis and heart failure via AMPK inactivation-mediated endoplasmic reticulum stress. Apoptosis. 2013;18(7):800-10

54. Yeh $\mathrm{CH}$, Chen TP, Wang YC, Lin YM, Fang SW. AMP-activated protein kinase activation during cardioplegia-induced hypoxia/reoxygenation injury attenuates cardiomyocytic apoptosis via reduction of endoplasmic reticulum stress. Mediat Inflamm. 2010;2010:130636.

55. MacLellan JD, Gerrits MF, Gowing A, Smith PJ, Wheeler MB, Harper ME. Physiological increases in uncoupling protein 3 augment fatty acid oxidation and decrease reactive oxygen species production without uncoupling respiration in muscle cells. Diabetes. 2005;54(8):2343-50.
56. Boudina S, Sena S, O'Neill BT, Tathireddy P, Young ME, Abel ED. Reduced mitochondrial oxidative capacity and increased mitochondrial uncoupling impair myocardial energetics in obesity. Circulation. 2005;112(17):2686-95.

57. Ozcan C, Palmeri M, Horvath TL, Russell KS, Russell RR 3rd. Role of uncoupling protein 3 in ischemia-reperfusion injury, arrhythmias, and preconditioning. Am J Physiol Heart Circ Physiol. 2013;304(9):H1192-200.

58. Perrino C, Schiattarella GG, Sannino A, Pironti G, Petretta MP, Cannavo A, Gargiulo G, llardi F, Magliulo F, Franzone A, et al. Genetic deletion of uncoupling protein 3 exaggerates apoptotic cell death in the ischemic heart leading to heart failure. J Am Heart Assoc. 2013;2(3):e000086.

59. Yasue H, Yoshimura M, Sumida H, Kikuta K, Kugiyama K, Jougasaki M, Ogawa H, Okumura K, Mukoyama M, Nakao K. Localization and mechanism of secretion of B-type natriuretic peptide in comparison with those of Atype natriuretic peptide in normal subjects and patients with heart failure. Circulation. 1994;90(1):195-203

60. Watanabe S, Shite J, Takaoka H, Shinke T, Imuro Y, Ozawa T, Otake H, Matsumoto D, Ogasawara D, Paredes OL, et al. Myocardial stiffness is an important determinant of the plasma brain natriuretic peptide concentration in patients with both diastolic and systolic heart failure. Eur Heart J. 2006;27(7):832-8.

\section{Publisher's Note}

Springer Nature remains neutral with regard to jurisdictional claims in published maps and institutional affiliations.

\section{Ready to submit your research? Choose BMC and benefit from:}

- fast, convenient online submission

- thorough peer review by experienced researchers in your field

- rapid publication on acceptance

- support for research data, including large and complex data types

- gold Open Access which fosters wider collaboration and increased citations

- maximum visibility for your research: over $100 \mathrm{M}$ website views per year

At BMC, research is always in progress.

Learn more biomedcentral.com/submissions 